\title{
Effects of a videogame in math performance and anxiety in primary school
}

\author{
Mariana Rocha ${ }^{1}$, Pierpaolo Dondio ${ }^{1}$ \\ ${ }^{I}$ Technological University Dublin, mariana.rocha@tudublin.ie, \\ pierpaolo.dondio@tudublin.ie
}

\section{Abstract}

The present paper describes the design and evaluation of a videogame developed to support math education and overcome math anxiety (MA) at the primary school level. The game narrative is based on the history of math. The player travels back on time and meets on-player characters such as Pythagoras of Samos and Ada Lovelace, learning about how math was used during their times. The player is invited to play a minigame where the concepts shared by the characters are used as a strategy to win. The game's evaluation consisted of a pre and post-testing study that measured students' math performance and MA levels. The experiment also included a group interview to collect students' perceptions about the game. The experiment lasted five weeks, and 88 students from three primary schools played the game on weekly sessions 45-60 minutes long. Statistical analysis suggested the game significantly improves students' math performance. However, the results indicated that female students from one of the classrooms had higher MA levels after playing the game. In addition, qualitative data shows students had a high level of engagement with the gameplay.

Keywords: game-based learning, math anxiety, primary school, history of math.

\section{Introduction}

Children start to have contact with mathematics from an early stage and, up to age five, develop ideas such as the concept of shape, patterns, and size[1], [2]. In the first years of school, pupils learn how to think in a more complex mathematical way, and some might demonstrate difficulty understanding math concepts, generating concern [3]. For some students, this difficulty can lead to frustration and lack of interest. Negative myths about mathematics are widespread in society, such as the idea that mathematics is complicated and tedious, resulting from a negative school learning experience [4]. Traditional learning approaches focus on procedural and inflexible knowledge, leading students to look at mathematics as a cold-blooded subject that not everyone can master. The research proposed 1,496 students from primary and secondary schools to write an essay with the theme "Me and Maths" [2]. The results suggest failures and unease characterize the essays, and students show a low perceived competence joint to the instrumental vision of mathematics. According to the authors, this is reinforced by repeated experiences perceived as failures when students feel they do not control their performance and conclude to be useless to work on it. 
In some cases, the negative experience while learning mathematics can lead to math anxiety (MA). This clinical condition is characterised as a collection of negative feelings associated with activities involving manipulating numbers and calculations [5], [6]. High MA levels can lead to poor performance at school and at work [7]. Interventions are proposed to overcome or prevent mathematics anxiety, such as adopting a game-based learning approach. Educational games can bring math to a context of problem-solving, making it more recognisable and less frightening. Games can simulate a variety of problem-solving situations, bringing meaning to abstract ideas and helping pupils to master concepts and skills [8], [9], [10]. The potential of educational games for math learning is recognised, but it is still unclear what type of game design implementation leads to successful learning and more positive perceptions concerning mathematics.

The present study is an extension of previous work [11] and contributes to exploring a math videogame' impact on math performance and MA levels. The game's mechanics are based on the situated learning approach using the history of mathematics as part of the narrative. The game's effects on the performance and MA levels were tested in Irish primary schools. The present study was motivated by the following research question (RQ):

RQ: What are the effects of a situated learning videogame on the mathematics performance and levels of mathematics anxiety in primary school students?

\section{Background}

This section will provide details about the research background. First, it highlights the connections between mathematics education and the use of educational games. Then, it presents the two main teaching approaches implemented in the game designed and evaluated during this research: situated learning and teaching from a historical perspective. Finally, the section describes Ireland's mathematics learning scenario, the country where the game was evaluated.

\subsection{Mathematics and game-based learning}

A lot of effort is being made to deliver design guidelines for the development of educational games. Still, game designers might provide exciting, fun games and miss the quality of teaching materials [12]. At the same time, educators struggle in finding the balance between the fun element of the game and the educational content [13]. Therefore, there is a need to evaluate what game design principles should be considered to improve learning outcomes and increase students' positive attitudes towards mathematics [14], [15]. When combined with appropriate pedagogical principles, technology may "open up new routes for students to construct and comprehend mathematical knowledge and new approaches to problem-solving" [16].

A review of 105 empirical studies about the use of videogames for primary school, [17] shed light on the characteristics of educational games currently used. They argued most of the effects of primary school games are knowledge acquisition and content understanding, followed by perceptual and affective motivational skills and cognitive skills. Still, primary school teachers seem to have more difficulty finding appropriate educational games for their students than secondary/high school teachers [18]. Many primary school games and 
educational software are drill and practice type [19], [20]. According to [21], videogames are not supposed to work in the same way as paper-and-pencils exercises as games are imaginary worlds meant to be lived in and experienced. Even games that claim to develop deep conceptual thinking do little more than "providing an opportunity to practice basic skills" [21]. Mathematics drill and practice usually leads to inert routine skills and repetition instead of flexible and reflexive learning [22].

\subsection{Situated learning and the history of mathematics}

Theories of education and teaching approaches underpin well-designed educational games. In the present research, the focus will be on implementing a game underpinned by situated learning. This cognitive theory claims effective education requires learning to be embedded in authentic contexts of practice [23]. In situated learning, the knowledge is obtained through contexts that reflect how the concepts can be applied in real-life situations, and what is learned can be implemented into a context or experience lived by the learner [24]. Games represent an opportunity for learning in a situated context [25], allowing students to use concepts learned in the classroom to solve daily life problems.

In the present paper, implementing a situated learning game is achieved by adopting the history of mathematics as a teaching method. Mathematics was developed to solve needs from daily life when there were no books to be consulted, and everything was empirically learned and constructed. According to [26], "historical analysis has been the basis for the theory that mathematics should be related to life situations", as the great civilisations developed this science to solve economic and social problems of their times. Therefore, it is possible to use the history of mathematics as a teaching tool, as it "lets children experience that mathematics is always developing, that it is continuously changing and that they are part of this evolution" [27]. Students may find comfort knowing that challenging concepts took thousands of years to shape into their final form [28].

There is lack in the literature about ways of adopting the history of math as a classroom teaching tool [29]. The use of a videogame developed to integrate history and mathematics may optimise the classroom time and is presented as a helpful resource for teachers that want to incorporate mathematics and its origin. Other digital media such as websites [30] and videoclips [31] were designed and tested, but the implementation of videogames with a historical narrative to support mathematics learning seems to be a field not well explored by researchers.

\subsection{Mathematics anxiety (MA)}

MA is a condition identified in primary school children [32], and its presence is associated with poor math performance at school. This condition can even affect students' future careers: a high MA level is related to inadequate drug dosages by undergraduate nurses [7]. Besides, MA can also lead to a lack of confidence, resulting in adverse effects on career choice [33]. Previous research studies have also demonstrated that pupils' gender plays an essential role in this condition's levels. Female students tend to have higher MA levels than male students [34], [35]. Besides, a study with second-grade students showed that the MA levels only moderated performance in girls [36]. Therefore, interventions to reduce MA should also consider genderspecific aspects. 
Although widespread studies about MA have been developed, it is still unclear what is the leading cause of this condition. Currently, the theories designed to explain MA causes fall into three main categories: poor mathematics skills [37], genetic predispositions [38], or socioenvironmental factors. A longitudinal study with 413 middle-school students showed a significant growth of MA at the end of sixth grade, highlighting the importance of early interventions [39]. A variety of strategies has been studied in an attempt to prevent or reduce MA, such as guided imagery sessions [40], cognitive tutoring [41], mindfulness sessions [42], and games [43], [44]. Still, more research is needed to comprehend better how these interventions act and in which situations they should be implemented.

\subsection{Education in Ireland}

The present study describes experiments that took place in Irish primary schools, which are currently ranked ahead of high-achieving countries such as Finland in standardised tests [45]. However, the students from these schools can have a low performance when demonstrating their problem-solving skills. A national assessment conducted with over 8,000 pupils showed that children from second and sixth classes scored, correctly, 54\% and $49 \%$ of the problemsolving questions [46]. Therefore, there is still room for further development in problemsolving training for the primary school level in Ireland, especially considering that the skills acquired during this educational level are fundamental to the following years. In Ireland, most primary school children are between 6 and 12 years old. A longitudinal study carried out in Ireland demonstrated that low math scores and negative math attitudes at the age of 9 have a strong influence on how children perform and engage with mathematics education at the age of 13 [47]. Another study with 356 students with age between 15 and 18 years old evaluated their attitudes towards mathematics. $72.8 \%$ of them confirmed that their past experiences influence their interest or disinterest in mathematics, and $33.1 \%$ said they do not use mathematics outside the school, showing they are not aware of this subject utility in everyday life [48].

\section{Research design}

\subsection{Design principles and game description}

The present study aims to understand the impact of an educational game designed based on situated learning principles on math performance and MA levels. Therefore, a situated learning digital game was developed and evaluated. Once Upon a Maths is an adventure videogame with a narrative based on the history of mathematics. The player aims to travel through time, solving challenges proposed by characters that are part of math history. The game is divided into three historical periods: ancient Egypt (3100 B.C.E - 30 B.C.E), ancient Greece (1100 B.C.E. -600 A.D.), and the modern world (from the $19^{\text {th }}$ century until nowadays). In each phase, an animation presents non-player ancient characters describing how mathematics was used to solve daily life problems during their times. The character then challenges the user to play a minigame with mechanics related to the content presented over the animation. Each historical period includes three minigames. If the player successfully wins all three minigames, $\mathrm{s} /$ he receives a stamp for completing that historical period, moving to the next one. 
The development of Once Upon a Maths considered three main components: an in-depth literature review of previous research, a multidimensional survey answered by 714 teachers, and the analysis of a collection of games adopted by those teachers in their classrooms. Some of the design principles adopted to develop the game are described in this paper. However, the details can be found in the doctoral thesis that originated the present paper [49].

Considering the game content, all minigames included in Once Upon a Maths are aligned with the official math curriculum for primary school education in Ireland [50] (Table 1).

Table 1 Once Upon a Math's' curricula coverage according to each minigame.

\begin{tabular}{|c|c|c|}
\hline Skill & Description & Minigames \\
\hline \multirow{2}{*}{$\begin{array}{l}\text { Counting and } \\
\text { numeration }\end{array}$} & Count the number of objects in a set & \multirow{2}{*}{$3,5,6$} \\
\hline & Estimate the number of objects in a set & \\
\hline $\begin{array}{l}\text { Extending and using } \\
\text { patterns }\end{array}$ & Recognize pattern, including odd and even numbers & 9 \\
\hline \multirow{4}{*}{ Operations } & $\begin{array}{l}\text { Develop an understanding of addition and subtraction by } \\
\text { combining or partitioning sets }\end{array}$ & \multirow{4}{*}{$3.5,6$} \\
\hline & $\begin{array}{l}\text { Develop and/or recall mental strategies for addition and } \\
\text { subtraction facts }\end{array}$ & \\
\hline & Use mental calculations & \\
\hline & Explore repeated addition and group counting & \\
\hline \multirow{3}{*}{ Length } & $\begin{array}{c}\text { Estimate, compare, measure and record length using non- } \\
\text { standard units }\end{array}$ & \multirow{3}{*}{1} \\
\hline & $\begin{array}{c}\text { Select and use appropriate non-standard measuring } \\
\text { units/instrument }\end{array}$ & \\
\hline & $\begin{array}{l}\text { Solve and complete practical tasks and problems involving } \\
\text { length }\end{array}$ & \\
\hline \multirow{2}{*}{ Weight } & $\begin{array}{l}\text { Estimate, compare, measure and record weight using non- } \\
\text { standard units }\end{array}$ & \multirow{2}{*}{3} \\
\hline & $\begin{array}{l}\text { Select and use appropriate non-standard measuring units and } \\
\text { instruments }\end{array}$ & \\
\hline \multirow{2}{*}{ Spatial awareness } & $\begin{array}{c}\text { Explore, discuss, develop and use the vocabulary of spatial } \\
\text { relations }\end{array}$ & \\
\hline & Give and follow simple directions & $2,7,8,9$ \\
\hline $\begin{array}{l}\text { Representing and } \\
\text { interpreting data }\end{array}$ & Sort and classify objects & 4 \\
\hline
\end{tabular}

Considering the game design, the genre adventure was adopted to train players to become better problem solvers [51]. According to [52], adventure games stimulate curiosity as the player always want to know what will happen next, besides provoking emotional proximity with the game and its characters. The reward system of the game was implemented with the aim of avoiding players feeling anxious. Once Upon a Maths does not include a leaderboard, especially considering that recent literature suggests leaderboards can have a negative effect on students who struggle with mathematics, reducing their motivation to play [53]. For every 
completed phase, the player received a virtual stamp from the ancient non-player character. Another element of the reward system is a printed passport provided to the child (Figure 1). The passport includes three pages where students get stickers as a reward for finishing each phase of the game, besides a collection of blank pages for students to draw/register their adventure through Once Upon a Maths. The passport also included a page named Good traveller. If a player finishes the minigames before the others, this student can help a colleague and gets a sticker for being a good traveller.

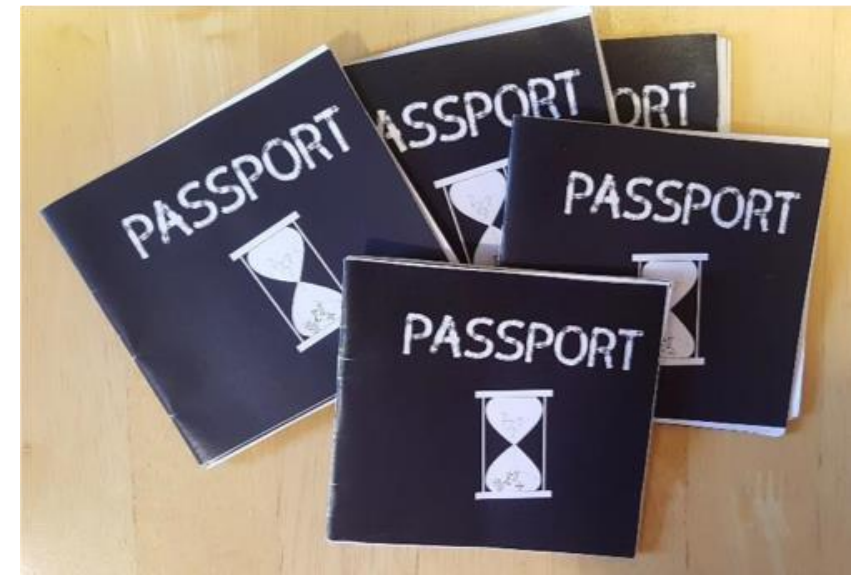

Figure 1. Printed passports were part of the reward system in Once Upon a Maths.

The guidelines of how to play were given both by the character during the animation video and written on the screen. Feedback was also given to children while they were playing. Every minigame presented a message in the screen that had instructions on how to play at the beginning of the game. After the first trial, the message changed to let the child know if s/he won - if not, the message always contained an idea of stimulating the player to try again.

The process of game design also considered the aesthetics of the game. In Once Upon a Maths, the scenarios, characters, and other elements are based on images identified in history books, paintings, and biographies. For instance, yellow was the most prominent color in the elements of the ancient Egyptian images, like the background of paintings [54], and this inspired the graphic design of phase 1. This phase also included some scenario elements based on the history of ancient Egypt, such as a scale based on the image shown in the Papyrus of Hunefer.. In this papyrus, the Egyptians describe the weighing of the heart rite, when the heart of the deceased is weighed in the scale against the feather of the goddess Maat who personifies order and truth[55]. Another example can be identified in phase 2, which illustrated math in ancient Greece. Most of the scenes contain white and pale colors, quite popular in ancient Greece due to the use of white marble in the architecture and sculptures.

Another aspect considered during the game design is how student's gender can influence their relationship with math [56]. There is evidence that females tend to be more anxious about mathematics than males, even when they have similar performance levels [36]. Knowing that in advance, the game was developed considering elements that could make the game attractive to females, like high use of visual learning approach [57], storytelling elements [58], and reduction of competitiveness [59]. Besides, adopting Ada Lovelace as one of the main characters aimed to inspire female players. For many years, Lovelace's achievements were not recognised. Today, to honour women in STEM, Ada Lovelace Day was created, and it is 
celebrated every second Tuesday of October. This character is relevant to Once Upon a Maths to introduce the player to the concept of algorithms and because she represents a female mathematician. In comparison to men, women are highly misrepresented by the media in STEM characters [60]. This might result in a lower number of girls pursuing careers in STEM when they grow up. In Ireland, less than 25\%, in Science and Technology based careers [61].

Considering the technical aspects of the game, Once Upon a Maths is a 2D game that can be easily accessed through most of the popular web browsers. When accessing the game, the player finds a landing page where s/he can insert their details to log into the system or register as a new user (Figure 2).

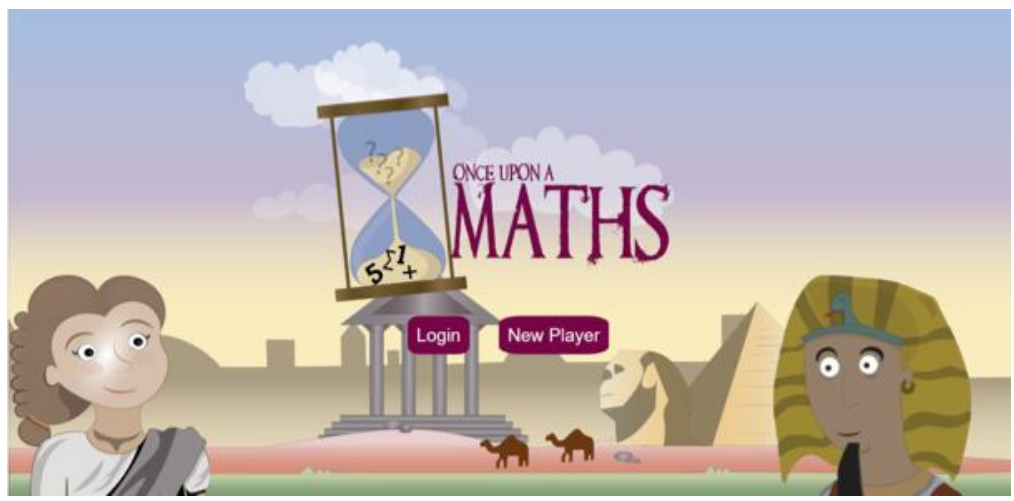

Figure 2. Landing page of Once Upon a Maths.

After that, the user has access to the page that shows nine islands, each representing one of the minigames according to the historical period (Figure 3). If the player is accessing the game for the first time, all levels will be locked except for the first one.

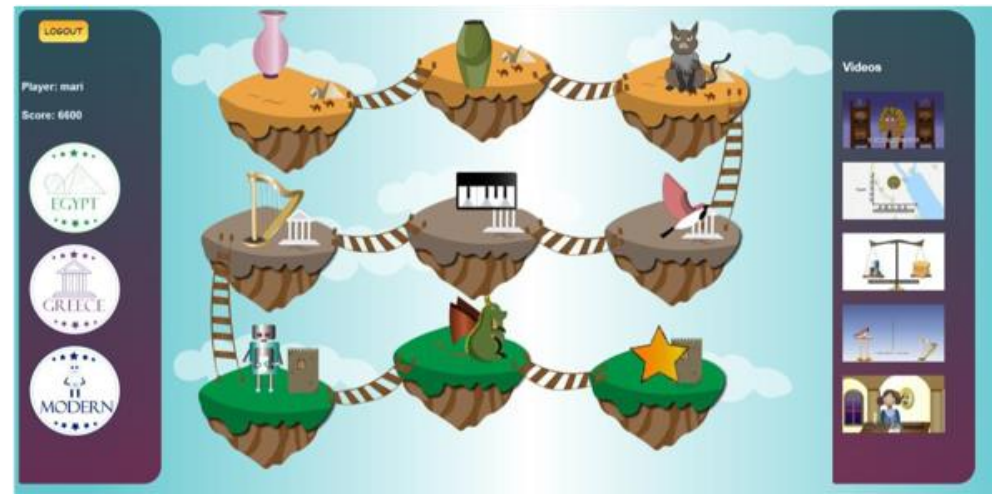

Figure 3. Minigames in Once Upon a Maths.

Phase 1 of the game starts with Nebamun, a sculptor from ancient Egypt, describing how people from his time used parts of the body as a measuring tool. He describes the concepts of cubit, foot and palm, explaining that a cubit is the distance from the elbow to the fingertips, while the foot has the size of a foot and a palm has the size of a hand. The animation shows the measurements and compares their sizes to the sizes of different animals (Figure 4). 


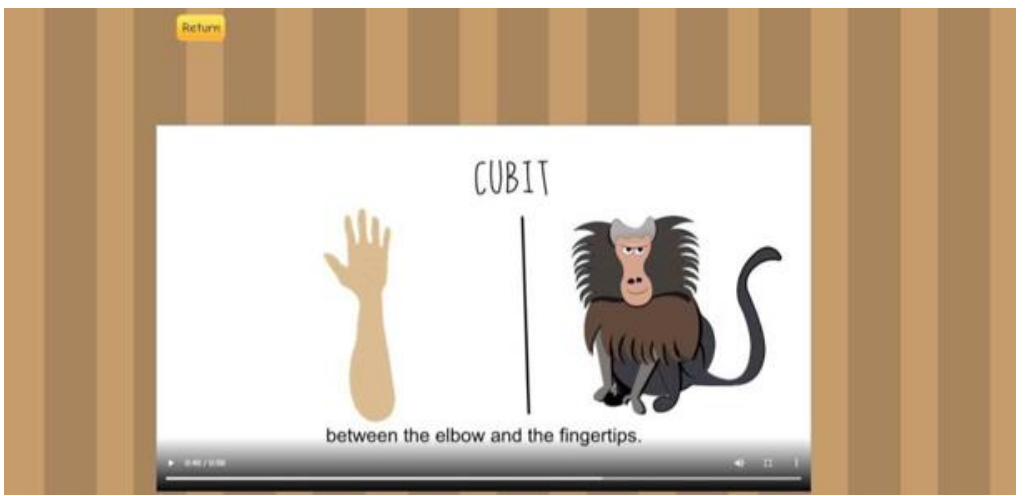

Figure 4. In the first phase of the game, Nebamun compares the parts of the body measurements with the size of animals.

After watching the animation, the player is invited to solve the first minigame: a drag and drop activity where the player must use parts of the body to measure vases sculpted by Nebamun. On the left side of the screen, a platform with a vase is shown, and the player should drag and drop parts of the body s/he thinks would match the size of that vase. The player can drop more than one part of the body - for example, measuring the vase using one foot and two palms - or only one - for example, measuring the vase using one cubit (Figure 5). There is a "clear" button that allows the player to remove dropped pieces and start again. Each part of the body that the player can drag contains a counter with the number of pieces dropped. Every time a piece is dropped, the counter is incremented by one.

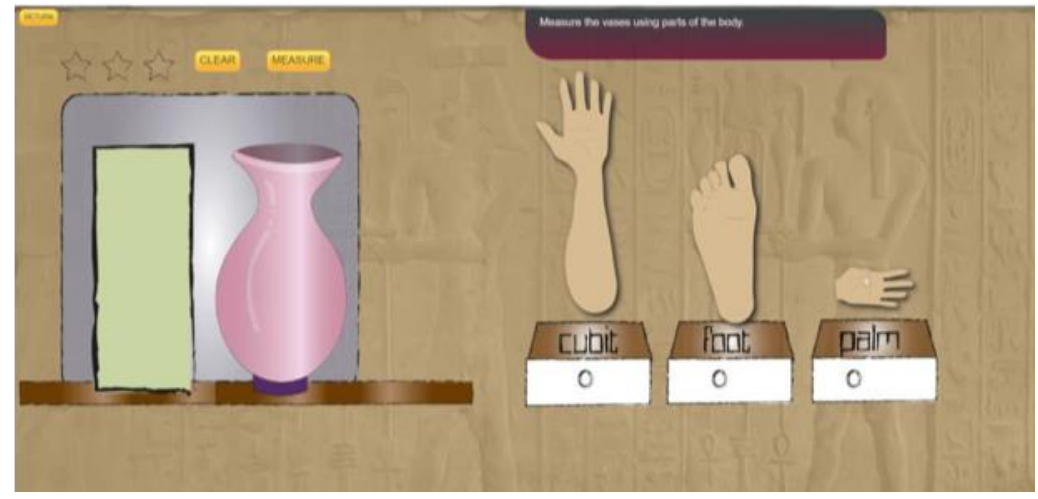

Figure 5. In the first phase of the game, Nebamun compares the parts of the body measurements with the size of animal

When the player clicks on the button "measure", the system checks if the answer is correct. In case it is, the platform opens, and the vase goes down so a new vase with a different size can appear, and the player can keep playing. Each star on the left side of the screen represents one vase to be measured. If the player inputs an incorrect answer, the vase breaks and the minigame restarts. If the player measures the three vases correctly, s/he gets 100 points and goes back to the level page to go to the next minigame. The second minigame is preceded by Nebamun explaining the concept of coordinates and how they can help find places on a map (Figure 6). 


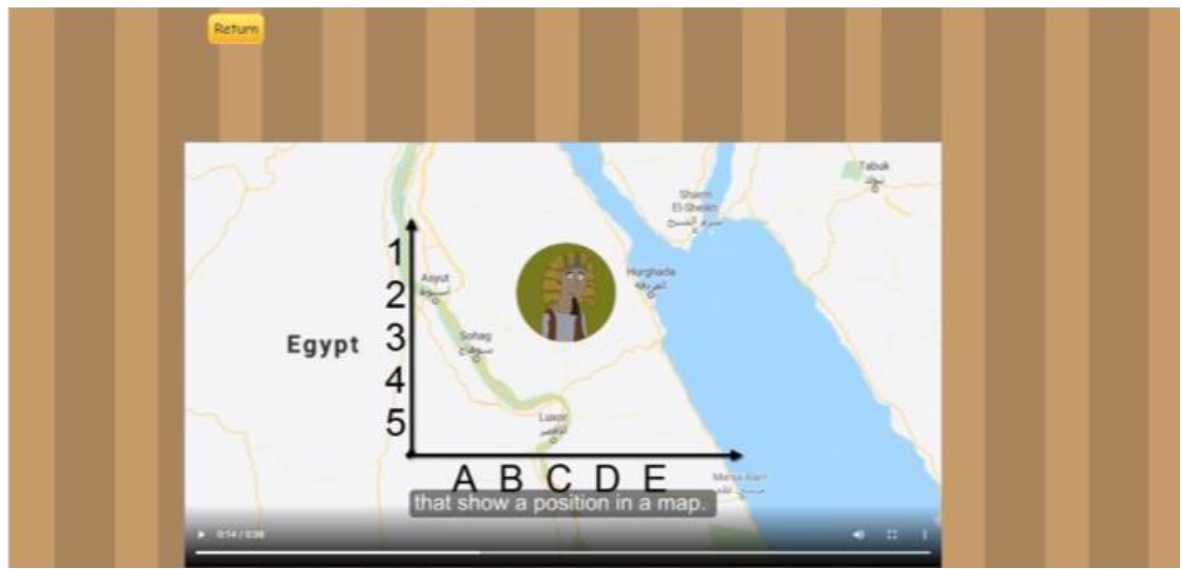

Figure 6. The second animation introduces the concept of coordinates.

The objective of the second minigame is to move the vase around a labyrinth following the coordinates indicated by Nebamun. The screen contains the labyrinth on the left side, and each line is represented by numbers, while the columns are represented by letters (Figure 7). The coordinates are presented on the right side, above the arrows that the player can use to move the vase.

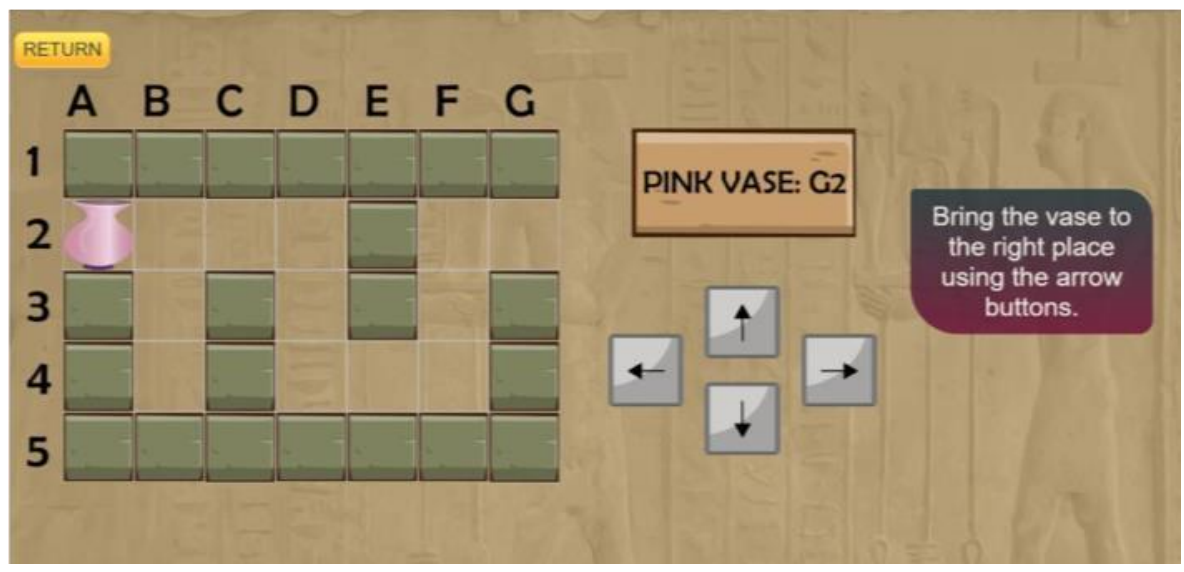

Figure 7. In the minigame 2, the player follows the coordinates to carry the vase around the labyrinth.

If the vase is moved to the right place, it becomes yellow, and the instructions change, telling the player to press the button to move to the next challenge. When the player does it, the vase that was moved before disappears, and a new vase appears at the beginning of the maze, and the coordinates change. If the player puts the three vases in the right place, s/he gets 100 points and goes back to the level page, where the next minigame is unlocked.

In the third animation, Nebamun explains that the weighing system was born with the discovery of metalworking. People from his time used pieces of metal with different weights that were placed in one of the plates of a scale to compare with what was placed in the other plate - for instance, food and animals (Figure 8). This animation introduces the third minigame, 
where the player will have to use pieces of metal with different weight values to check how heavy a specific animal is.

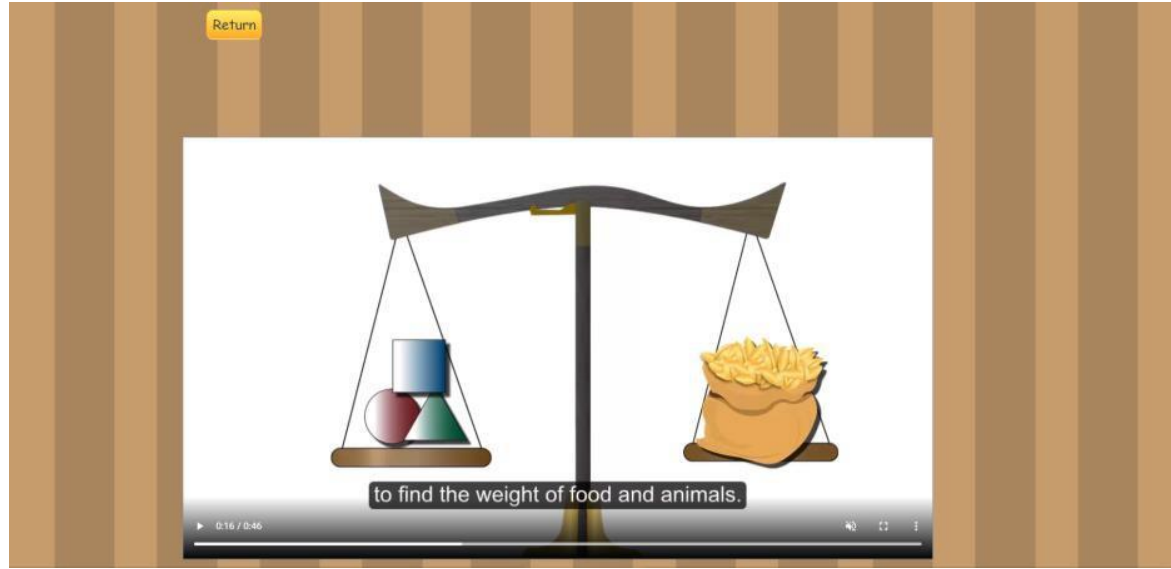

Figure 8. The third animation describes the weighing system used in the Ancient Egypt.

The aim of minigame 3 is to balance the weight of the bird with the weight of metal pieces. It is a drag-and-drop game, and the left side of the screen shows the pieces of metal. The metals are distributed in a grid where the lines determine the weight of each metal, and the columns describe the number of elements contained on that shelf (Figure 9). The player should drag and drop the right number of pieces to the empty plate to balance the metal and the animal weight. Then, by pressing the blue circle in the centre of the scale, the system checks if the weights are correct.

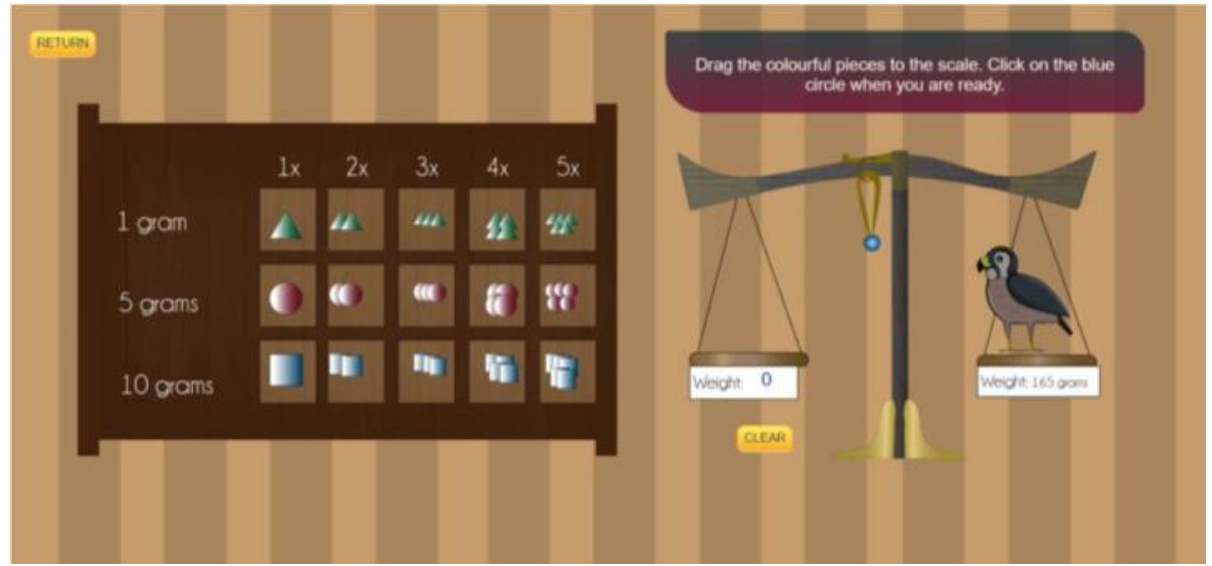

Figure 9. The aim on minigame 3 is to find the balance between the metal pieces and the animal

If the metals are heavier than the animal, the first plate goes down, and the animal spins away. If the opposite happens, the plate with the animal goes down to show it is heavier than the metal. If both weights are the same, the player moves to the next stage and weighs another animal. There are three animals to weigh in this minigame. If the player finds the correct weights for all three animals, s/he gets 100 points and goes back to the level page. This level is finished, and the player gets a stamp for completing ancient Egypt level, unlocking phase 2. 
The second phase is presented by the philosopher Pythagoras, from ancient Greece (Figure 10 ), in an animation that introduces all three minigames. In the video animation, Pythagoras is accompanied by a bird that gets confused when the philosopher states to be known as the father of mathematics and the father of music. Pythagoras then explains how math and music are related, showing the connection between fractions and musical notes. The animation was inspired by the registers that describe a moment when Pythagoras heard hammers in a blacksmith's forge and found them very pleasant to the ears. He then decided to check the weights of the hammers and discovered that these were related to ratios of whole numbers. Excited about his discovery, Pythagoras invented the monochord and realized a harmonic relationship between the sounds of strings with different lengths [62]. Thus, he came up with the idea that music harmony, or a pleasing combination of sounds, can be achieved when string length ratios involve the numbers $1,2,3$, and 4 .

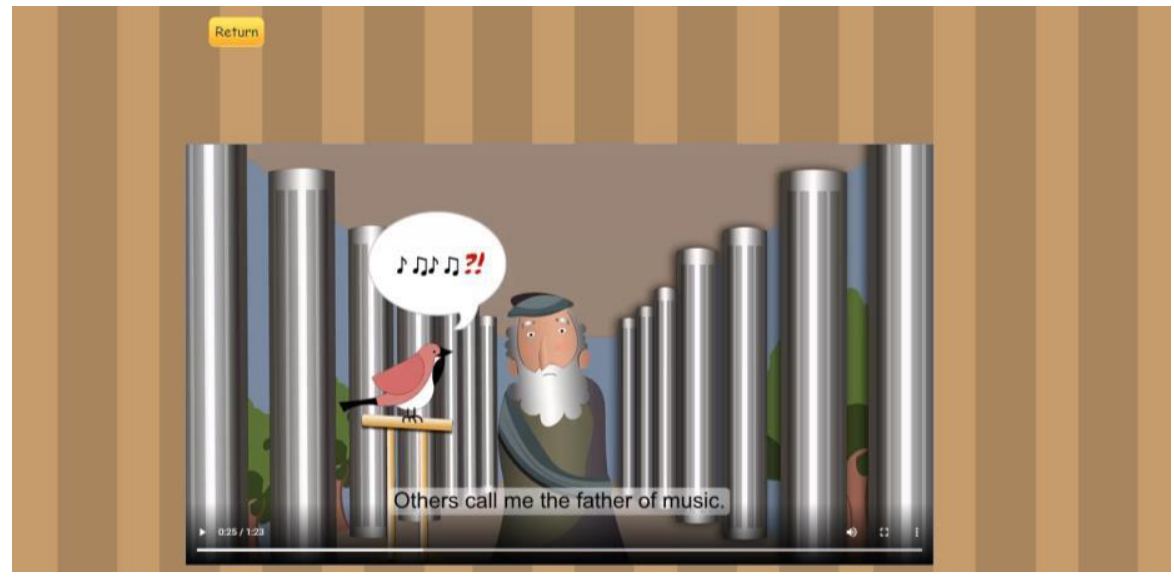

Figure 10. Pythagoras introduces the connection between music and math.

The player then progresses to minigame 4, a sorting activity. The screen shows a harp containing pieces of different sizes that represent musical notes. The player should organize those pieces according to their size (Figure 11). After that, the player presses the "play" button and, if the order is wrong, the instructions on the right side tells them to try again. If the order is correct, the player wins 100 points and listens to the sound of the notes. S/he then is instructed to press the button "next", which allows the player to go back to the level page and go to the next minigame. 


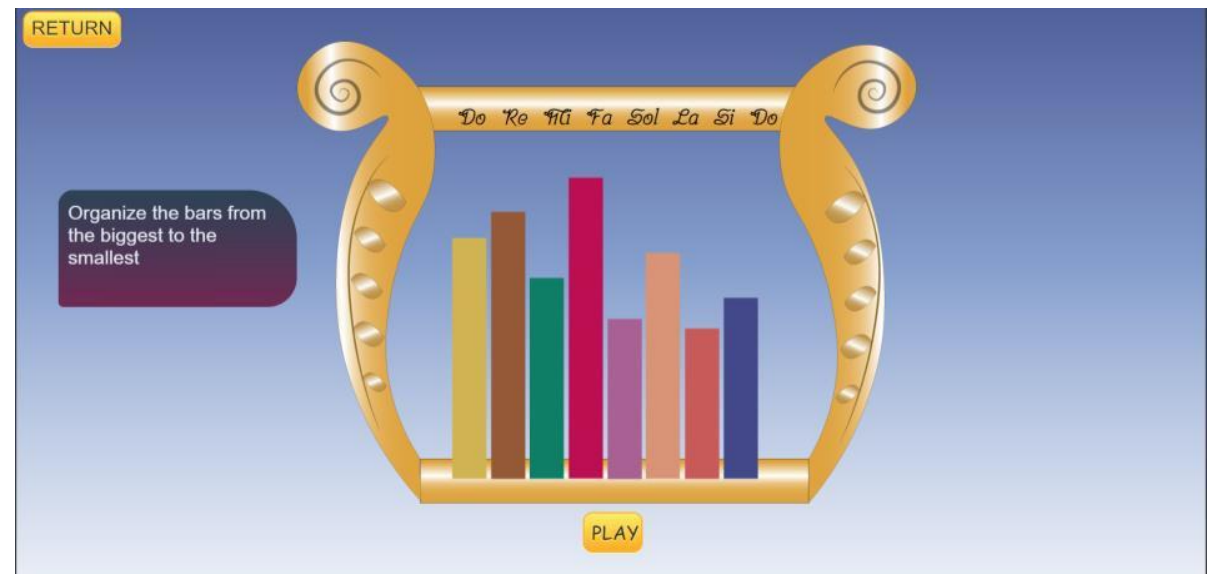

Figure 11. In the minigame 4, the player needs to consider the fraction that represents each musical note and represent those according to the size.

The minigame 5 is a drag and drop game. The aim is to match the pieces on the left side with the keys of a piano. Each piece contains circles, and they should match the number above the key. After matching all the pieces, the player presses the button "play". If the order is incorrect, the instructions let the player knows that s/he should try again, highlighting where the mistakes were made (Figure 12). If it is correct, the player listens to the piano notes.

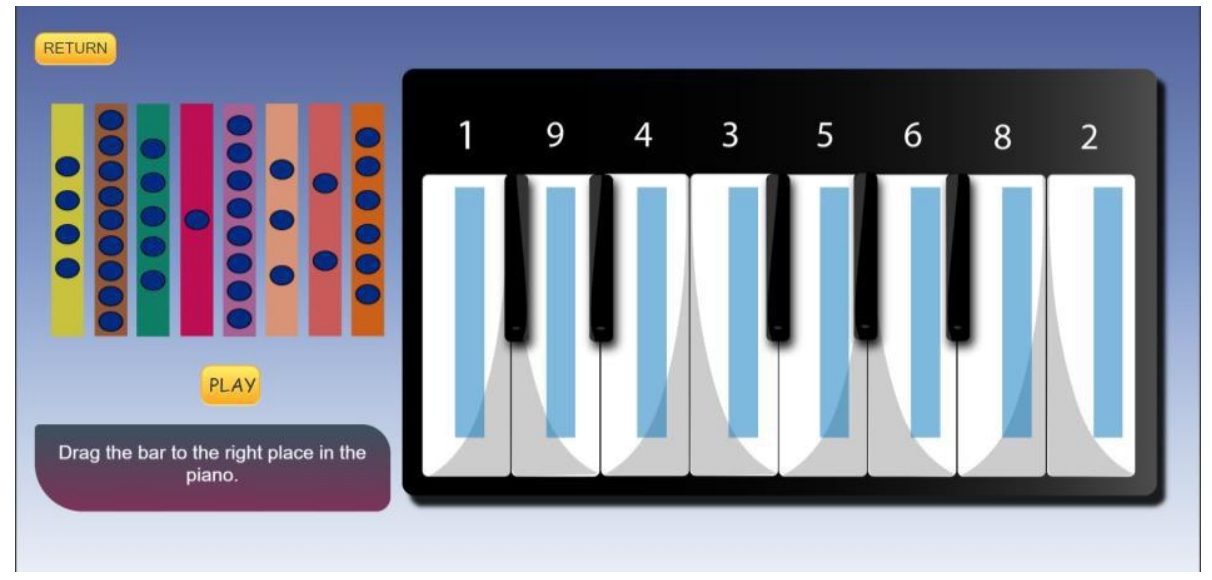

Figure 12. In the minigame 5, the player should match the pieces with the quantities represented by circles with the numbers displayed above the keys in the piano.

In the minigame 6 , the player must follow a music sheet, where each note is represented by a number (Figure 13). The piano keys contain the same pieces with circles from the previous minigame. The player should press the keys following the order on the music sheet. Every time a key is pressed, the player can hear the note. After that, s/he should press play. If the order is correct, the music sheet changes, and the player plays the second part of the song. The song is "Happy Birthday", and is divided into three music sheets. After playing the music sheets correctly, the player gets 100 points and a stamp for finishing the challenges of phase 2 of Once Upon a Maths. The player then goes back to the level page to move to phase 3 . 


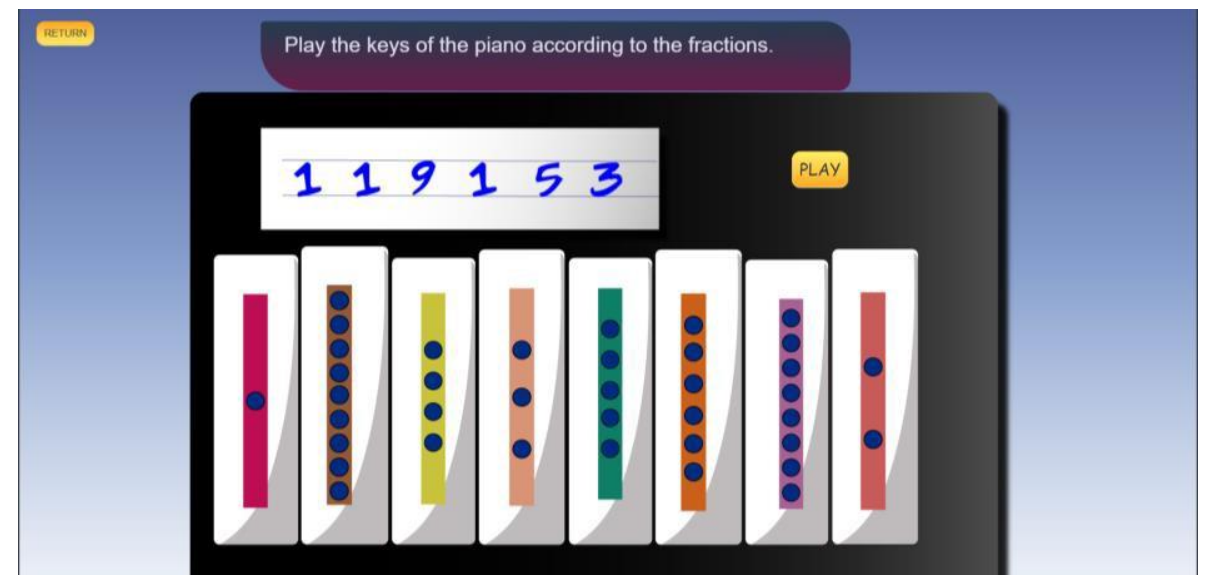

Figure 13. In the minigame 6, the player follows a numerical music sheet to play a song.

The third phase is presented by the character Ada Lovelace, an English mathematician considered by many researchers the first computer programmer [63]. She exchanged letters with Charles Babbage, who created the analytical engine, a machine that could to make complex calculations [64]. While translating an article about the machine, Lovelace added an algorithm that the machine could use to calculate the sequence of Bernoulli numbers, a sequence of rational numbers which frequently occur in number theory. In the animation, Ada Lovelace explains Babbage's machine and the concept algorithm, describing why it is important to write correct instructions so a machine can execute functions in the way it is expected to do (Figure 14). 


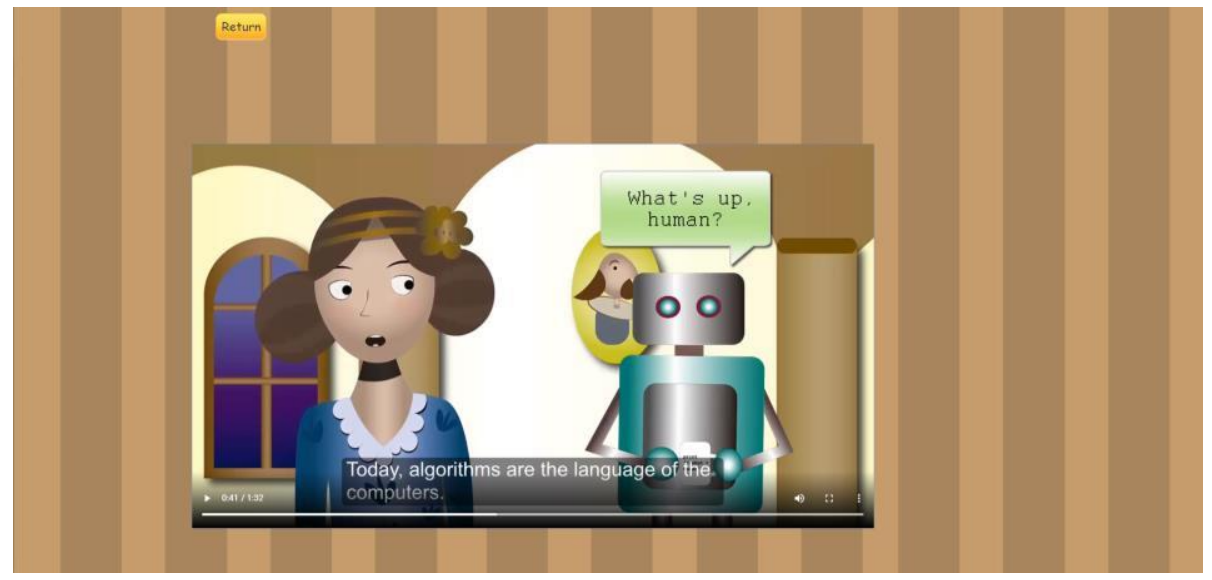

Figure 14. Ada Lovelace explains how algorithms work.

Lovelace also talks about her passion for flying. At the age of 12 years old, she studied the patterns of birds' wings, researched different materials, like feathers and silk, and worked on sketches of steam-powered flying machines [64]. Lovelace then challenges the player to use algorithms to teach an animal how to fly by solving the minigames 7,8 , and 9 , which are similar but have different levels of difficulty. These minigames aim to teach an animal how to fly. The player can choose between a unicorn or a dragon. The screen shows, on the left side, a column with numbers. In the middle, the clouds where the animal should jump into. Each cloud is referent to one of the numbers at the column, and the player should use that to guide the animal, telling it to fly to a cloud referent to a certain number and to which direction the animal should fly. The instruction is given by dragging and dropping pieces with numbers (referent to the clouds) and arrows (referents to the direction). There are boxes categorized by order of steps on the right side of the screen, where the player should drop the instructions pieces. If the player makes a mistake, s/he can press the button clear next to the step box (Figure 15).

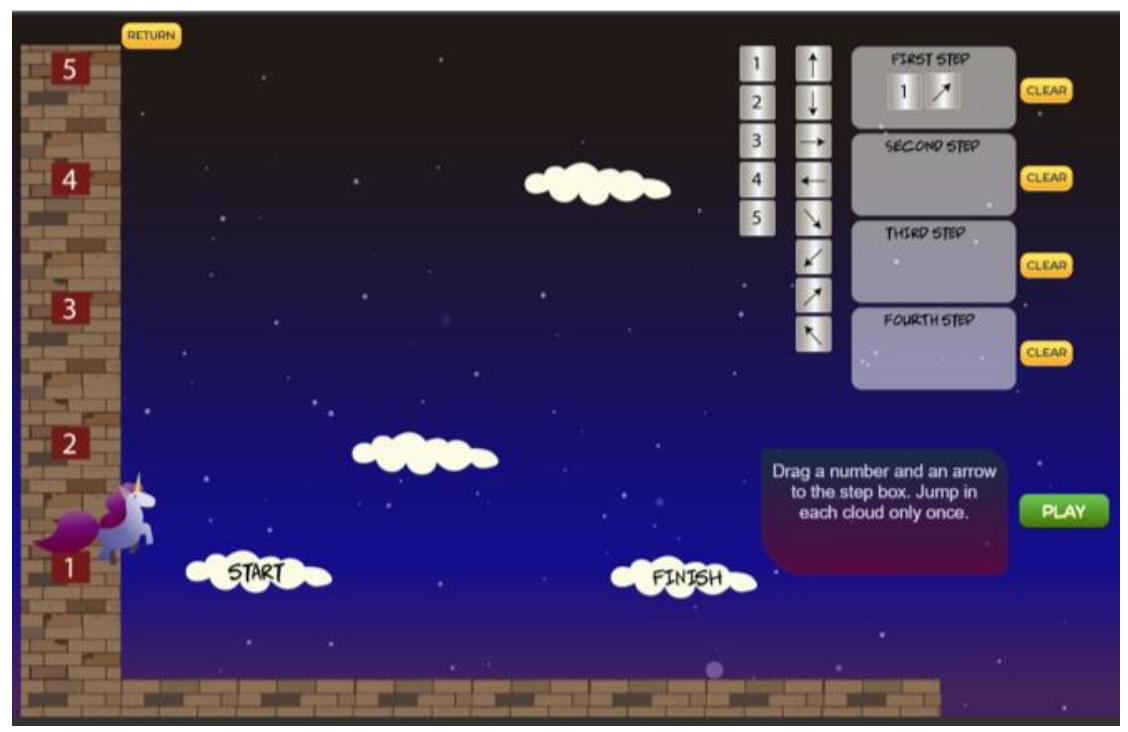

Figure 15. In the minigames 7,8 and 9 , the player needs to build an algorithm to teach the animal how to fly. 


\subsection{Empirical experiment}

\subsubsection{Overview}

A within-subjects design experiment was carried out with primary school students to answer the research question. In this research design, the participants are evaluated in different moments - in the present study, before and after playing the game. No control group is included as each subject is their own control. This type of experiment is particularly common in educational research to evaluate interventions' effects on the learning process [65]. The differences between the pre and post-tests will reveal if Once Upon a Maths impacts students' math performance and MA levels. Section 3.2.2 describes the tools used to collect these measurements.

The experiment was performed with primary school students from Irish classrooms for 5 weeks. Two researchers from our team visited each classroom once per week for sessions between 45 to 60 minutes long. The visits were scheduled to take place at the time allocated for their math class. No other activity happened during that time except for our gameplay sessions. During the rest of the week, students had their regular schedule taking place. During the experiment, the teachers were in the classroom but did not interfere unless to solve issues not related to the research. In the first visit, the researchers presented the game and explained how the following gameplay sessions would be carried out. We made clear to the students they were not obliged to participate in the experiment as the results would not count as official school evaluations. Students received an assent document, besides bringing home a consent document to be signed by their parents. Next, the students answered two pre-tests to evaluate their math performance and MA levels. The following three weeks consisted of gameplay sessions. On the fifth and final visit, students answered the math performance and math anxiety post-tests, besides participating in a group interview to collect their perceptions about the game. The following diagram illustrates the activities carried out along the 5 weeks (Figure 16).

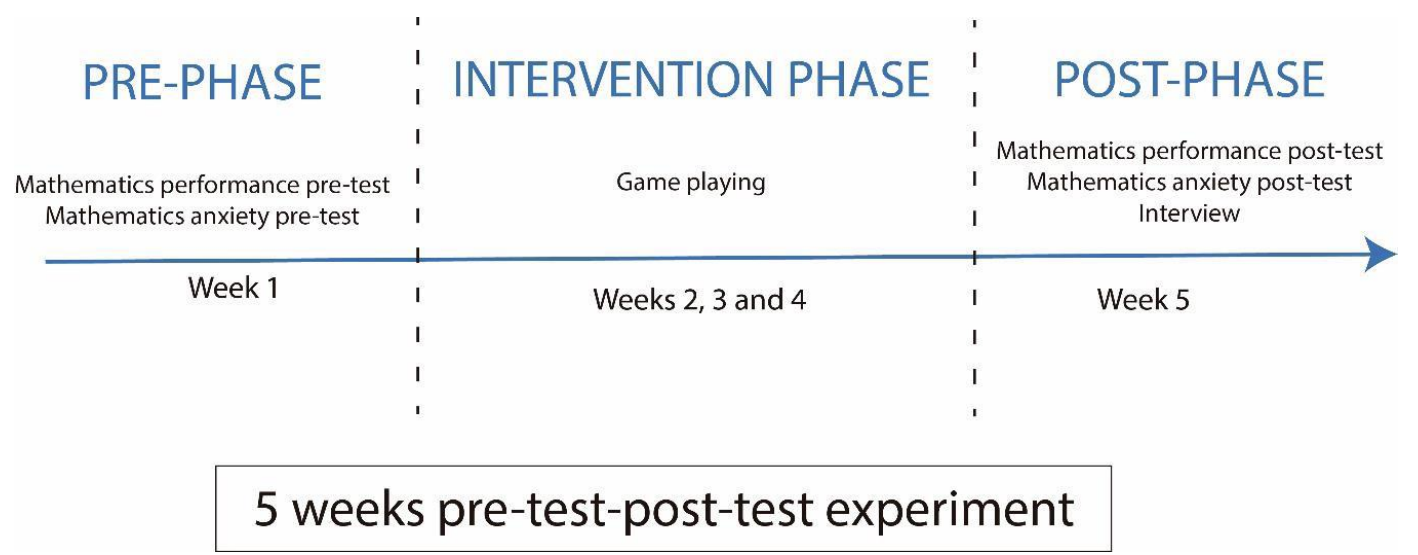

Figure 16. The experiment was carried out along 5 weeks. The researchers visited the classroom once per week.

\subsubsection{Pre-post-test questionnaires}

In both pre and post-test phases, students' performance was measured through a math questionnaire that covered the content presented on the game. The pre and post-tests for math performance are similar, with some minor changes in the order of the questions and some of 
the values on the calculations. This was implemented to guarantee children do not perform well on the post-test because they recall answers from the pre-test. In both pre and post-test phases, the levels of MA were measured using the modified Abbreviated Mathematics Anxiety Scale (mAMAS) [66], a reliable and validated questionnaire design for primary school students. The mAMAS is a self-report questionnaire with nine items. Children use a 5-point Likert scale to indicate how anxious they feel when dealing with situations that involve math, being 1 equal to low anxiety and 5 equals to high anxiety. The higher is the result, the more anxious the child is. Both questionnaires were formatted to be more readable for young children, printed using large font size. In addition, the mAMAS included sad and happy emoticons at the endpoints of the Likert-scale to aid students in their responses. Both math performance and math anxiety questionnaires were read aloud before the experiment, so students could ask questions and make sure they understood the tests. Then, the students answered the questions by themselves.

During the three weeks between the pre and post-tests, the students played each of the three main phases of the game. In Ireland, the average class size is around 25 students [67]. Therefore, 30 tablets computers were brought to the classrooms for the game playing sessions. Students also received the printed passports with their username and password to access the game.

As participation was anonymous, researchers do not have access to students' names, only their game usernames. Teachers participated in filling a spreadsheet linking students' usernames in the games to the demographic data, such as students' gender. All procedures were approved by the Technological University Dublin Ethics Committee (TU Dublin Research Ethics Committee approval number REC-17-29). All participant researchers applied to be Garda vetted, a procedure of background check completed by the National Vetting Bureau and required for those carrying out relevant work with children or vulnerable persons.

\subsubsection{Group interview}

Students' perceptions about the game were collected through a group interview, which was recorded and transcribed. The interview was guided by open-ended questions such as their most and least favourite aspects of the game, the emotions they felt while playing, and what elements they would change on the game. The researchers ensured students were aware they could express their opinions, even if they had negative perceptions about the game.

\subsubsection{Data analysis}

The analysis of the results was carried out through statistics techniques using the software IBM SPSS Statistics 21. The statistical analysis follows a protocol proposed by [68], and a comparison of pre and post-results of math performance and math anxiety tests was carried out. Wilcoxon signed-rank test was used to identify if there is any difference between the pre and post-tests. An analysis between the two groups of female and male students considering the MA levels was done using Mann-Whitney U Test. If the difference between the two groups is significant, an analysis to check if there is an influence of the participant's gender was carried out using Analysis of covariance (ANCOVA). According to [68], when these two groups of students have a significant difference in MA levels before the intervention, this has to be considered a covariant when comparing the pre and post-tests. Due to the relevance of the social environment's aspects, all the analysis previously described were carried out considering specific scenarios. First, the data from the whole group of participants was evaluated. Then, a class-specific comparison was performed, and each classroom group was evaluated separately. 
The results of the group interview session will be presented through a reflection about students' perceptions of Once Upon a Maths.

\section{Results}

\subsection{Descriptive statistics and demographics}

Once Upon a Maths was tested by users from two schools (Figure 17). The first is a catholic co-educational (mixed-gender) school located in Dublin. Two classrooms from this school participated in the experiment and will be referred to as Classroom 1 (1st class of primary school) and Classroom 2 (1st class of primary school). The other school is a catholic rural coeducational school located in county Kildare. One classroom from this school participated of the present experiment and will be referred as Classroom 3 (2nd class of primary school). A total of 88 students participated of the study, 43 females and 45 males. Part of the data was incomplete because not every student attended school in every gameplay session. After cleaning the missing data, we evaluated data collected from 73 participants.

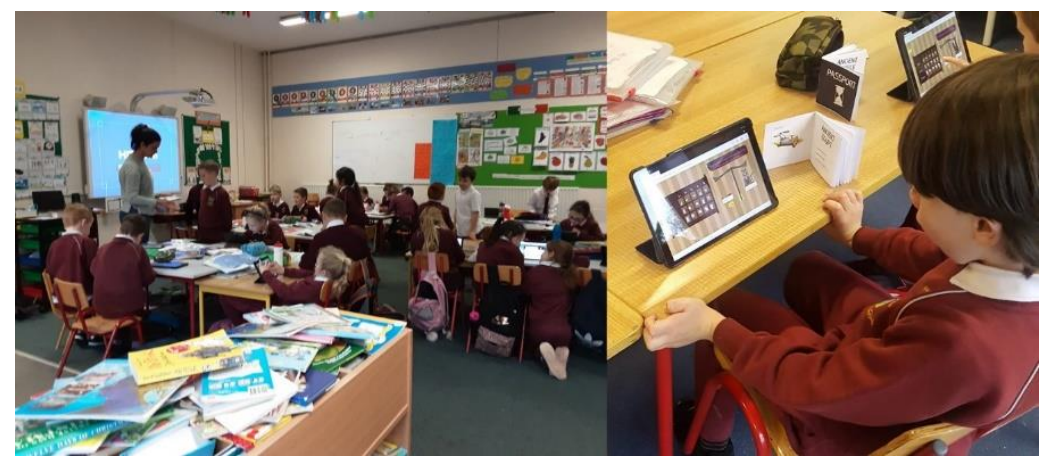

Figure 17. Students testing Once Upon a Maths.

The results of the math anxiety pre-test (maximum value of 45) show a mean score of 19.67, while the post-test had a mean of 20.53. The results of the math performance pre-test (maximum value of 10) show a mean of 7.05 , while the post-test had a mean of 8.3 (Table 2).

Table 2. Distribution according to the mean, standard deviation, and percentiles of the preand post-mAMAS and pre-and post-test for math performance.

\begin{tabular}{c|c|c|c|c|c}
\hline \multicolumn{2}{c|}{} & $\begin{array}{c}\text { Pre- } \\
\text { mAMAS }\end{array}$ & $\begin{array}{c}\text { Post- } \\
\text { mAMAS }\end{array}$ & $\begin{array}{c}\text { Pre-test } \\
\text { (performance) }\end{array}$ & $\begin{array}{c}\text { Post-test } \\
\text { (performance) }\end{array}$ \\
\hline \multicolumn{2}{c|}{ Mean } & 19.67 & 20.53 & 7.0504 & 8.32 \\
\hline \multicolumn{2}{c|}{ Std. Deviation } & 6.76 & 8.59 & 2.03 & 1.82 \\
\hline Percentiles & $\mathbf{2 5}$ & 14.50 & 14.00 & 5.50 & 7.50 \\
\hline & $\mathbf{5 0}$ & 21.00 & 19.00 & 7.50 & 8.33 \\
\hline & $\mathbf{7 5}$ & 24.00 & 27.50 & 8.30 & 10.00 \\
\hline & $\mathbf{9 0}$ & 30.00 & 32.60 & 10.00 & 10.00 \\
\hline
\end{tabular}


Considering [69], high MA levels were defined based on the scores at or above the 90th percentile, which corresponded to raw scores of 30 and above. In the present research, around $11 \%$ of the students that participated in the study had a score equal or above 30 points in the pre-mAMAS and $17 \%$ in the post-mAMAS. Table 3 describes students' distribution according to the results of pre- and post-tests for math anxiety and pre- and post-tests for math performance.

Table 3 Distribution of pre- and post-mAMAS and pre- and post-test for performance results according to students' gender.

\begin{tabular}{|c|c|c|c|c|c|}
\hline & & $\begin{array}{c}\text { Pre-test } \\
\text { (performance) }\end{array}$ & $\begin{array}{c}\text { Post-test } \\
\text { (performance) }\end{array}$ & $\begin{array}{c}\text { Pre- } \\
\text { mAMAS }\end{array}$ & $\begin{array}{c}\text { Post- } \\
\text { mAMAS }\end{array}$ \\
\hline \multirow[t]{4}{*}{ Male } & $\mathbf{N}$ & 38 & 38 & 38 & 38 \\
\hline & Std. Deviation & 2.02142 & 1.85415 & 5.499 & 6.909 \\
\hline & Median & 7.2500 & 8.0000 & 17.00 & 16.00 \\
\hline & Mean & 7.0311 & 8.0568 & 17.24 & 16.79 \\
\hline \multirow{4}{*}{ Female } & $\mathbf{N}$ & 35 & 35 & 35 & 35 \\
\hline & Std. Deviation & 2.08190 & 1.77918 & 7.083 & 8.483 \\
\hline & Median & 7.5000 & 9.0000 & 23.00 & 26.00 \\
\hline & Mean & 7.0714 & 8.6234 & 22.31 & 24.60 \\
\hline \multirow{4}{*}{ Total } & $\mathbf{N}$ & 73 & 73 & 73 & 73 \\
\hline & Std. Deviation & 2.03642 & 1.82831 & 6.764 & 8.599 \\
\hline & Median & 7.5000 & 8.3300 & 21.00 & 19.00 \\
\hline & Mean & 7.0504 & 8.3285 & 19.67 & 20.53 \\
\hline
\end{tabular}

\subsection{Inferential statistics on overall comparisons}

\subsubsection{Effects of the game on mathematics performance}

Our results suggest that students had a higher math performance after playing Once Upon a Maths, with a large effect size [70] $(\mathrm{z}=-4.407, \mathrm{p}=0.000011, \mathrm{r}=0.51)$. Therefore, Once Upon a Maths improves students' math performance.

The analysis of the pre-test for math performance considering students' gender suggests no difference between female students $(\mathrm{Md}=7.5, \mathrm{n}=35)$ and male students, $(\mathrm{Md}=7.25, \mathrm{n}=38)$ $(\mathrm{U}=651, \mathrm{z}=-0.150, \mathrm{p}=0.881, \mathrm{r}=0.017)$. Similar result is found when evaluating the post-test results, with female students $(\mathrm{Md}=9, \mathrm{n}=35)$ having similar performance as male students $(\mathrm{Md}=8, \mathrm{n}=38)(\mathrm{U}=524, \mathrm{z}=-1.608, \mathrm{p}=0.108, \mathrm{r}=0.18)$. Therefore, both genders have similar levels of performance in math before and after playing the game.

\subsubsection{Effects of the game on mathematics anxiety}

To identify if the game has any effect on the levels of MA, statistical analysis was conducted to compare the pre and post-mAMAS tests answered by the students. The results suggest the game does not affect students' levels of MA $(z=-0.929, p=0.353)$. The analysis of the MA test scores before playing the game suggests female students $(\mathrm{Md}=23, \mathrm{n}=35)$ had a significantly higher MA than male students $(\mathrm{Md}=17, \mathrm{n}=38)(\mathrm{U}=384, \mathrm{z}=-3.111, \mathrm{p}=0.02, \mathrm{r}=0.36)$. Similar result is found after playing the game, with female students $(\mathrm{Md}=26, \mathrm{n}=35)$ being significantly more anxious than male students $(\mathrm{Md}=16, \mathrm{n}=38)(\mathrm{U}=308, \mathrm{z}=-3.948, \mathrm{p}=0.000079, \mathrm{r}=0.46)$. Due 
to this result, an ANCOVA was performed considering the pre-mAMAS results as a covariate to check how much the gender influenced the differences between pre and post-mAMAS. The results suggest that playing Once Upon a Maths might have increased the MA levels only for female students, with a $\mathrm{p}=0.017$ and a partial eta squared $=0.079$. Therefore, the results suggest that $7.9 \%$ of the increase of the MA levels after playing the game can be related to gender, which is a small effect size. The results then confirm that those female students had higher levels of MA after playing the game.

\subsection{Inferential statistics on classroom-specific comparisons}

The current research was performed in three different classrooms, and each can be considered a specific environment with social aspects that might influence the students' perceptions of math. Therefore, we decided to perform the same analysis previously described considering each classroom as a separated sample of students. In all classrooms, playing Once Upon a Maths increased students mathematics performance. When evaluating the effect of the game on MA levels, only in classroom 3 (2nd class) female students had higher MA levels after playing. For classroom 3, the comparison between female $(M d=24, n=9)$ and male $(M d=13$, $\mathrm{n}=15$ ) students' MA levels before playing the game reveals significant differences ( $U=22, \mathrm{z}=-$ 2.726, $\mathrm{p}=0.006, \mathrm{r}=0.32$ ). Similar results can be found when looking at the levels of MA after playing Once Upon a Maths, as female $(M d=29, n=9)$ and male $(M d=12, n=15)$ students had significant differences between their MA levels in the post-test $(U=13, z=-3.261, p=0.001$, $\mathrm{r}=0.38$ ).

ANCOVA was performed considering the pre-mAMAS results as a covariate to compare if the score differences between pre and post-mAMAS had any difference when considering the student's gender. Playing Once Upon a Maths impacted the MA levels when adjusting it for the pre-intervention and considering student's gender $(\mathrm{p}=0.028$, partial eta squared $=0.209)$ for classroom 3. This partial eta square reveals that $20.9 \%$ of the changes in the levels of mAMAS after playing the game can be related to gender, which is large effect size. Therefore, only in one of the three classrooms, females tend to get more anxious after playing Once Upon a Maths, while males' MA levels do not change.

\subsection{Students' perceptions about the game}

In the final week of the experiment, students took part in a group interview. The first question of the interview was "Which game you liked the most: Ancient Egypt, Ancient Greece, or Modern World?". Most students in the second class said they preferred Modern world minigames. The reason, according to the students, is that those minigames were more challenging than the others. In the first class group, most children preferred Ancient Egypt and Ancient Greece phases, as they could "play music" and "measure stuff". Many of those said they did not like Modern World because "it was too hard". It was quite clear that different children have different levels of difficulty and, although some get motivated by the challenges, others felt it was disengaging. One child from the second class said the Modern world was the best part of the game "because it was very different from the other ones and there wasn't a lot of math on it". Another student from the first class said, "I love the game", but, when asked if s/he liked math, answered, "no, I hate math". Finally, one of his/her friends said, "but the game is about Maths", to what the first student answered with a confused face. They both laughed and changed the subject.

When asked what s/he would change in the game, a student from the second class said: "I would make it easier", while another said "I would make it harder". Then, a third child 
interfered and said: "You could set up a difficulty setting on it so people could pick how hard the game would be".

When asked what game was the hardest one and the easiest one, most children from the first and second classes said Modern World and Ancient Egypt. This is in line with the aim of the game: to show that math is a process and became more sophisticated through time.

The narrative and the inclusion of real-life characters gave scope to students' imagination. Most had Ada Lovelace as their favourite character. In one of the first class groups, a child said the unicorn, from the Modern World phase, was their favourite character, then asked if the unicorn was real like Ada Lovelace was. Another student was very concerned that her unicorn fell many times and suggested to "have a person bringing the unicorn back to the place, so we don't think it died". Students' reproduced their connection with the characters while drawing them in the passports (Figure 18)

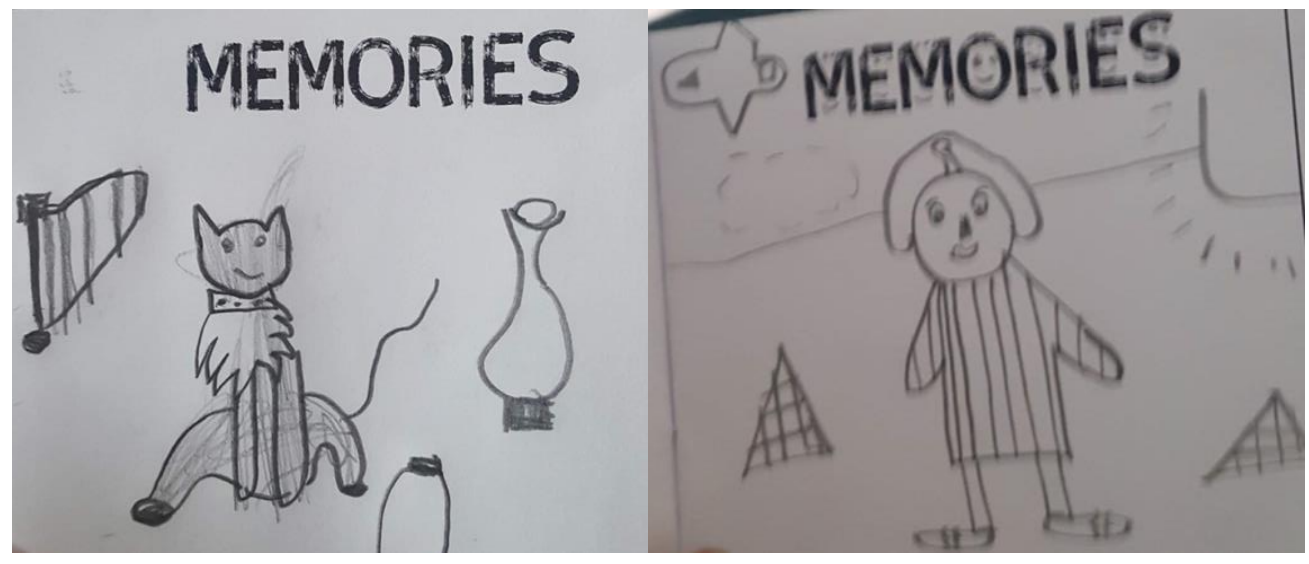

Figure 18. Students drew their memories on the passports.

They were also asked to describe in one word how they felt while playing, and most of the answers were positive. Words like "happy", "good", and "clever" were cited. Less frequently, some children said they felt "confused", "worried", and "bored". The students were also asked if they enjoyed working in a group for some of the challenges. All of them answered "yes" and, when asked why, some gave answers related to the good feeling of being helpful (e.g., "because I like being nice"); the spread of collaboration (e.g., "because when you help someone, he helps more people"), or the fact they learned more about the game when explaining it to another child (e.g., "because I got to figure out... If I didn't get something before I got it when I could do it again"). One of the students answered honestly, "I like to help because I get more stickers".

\section{Conclusions}

The main novelty of the present work consists of evaluating the effects of a situated learning game on the mathematics performance and math anxiety of primary school children. The game to be tested was designed and developed based on 3 years of research, including collecting and deploying information provided by teachers. The hypothesis is tested based on a structured empirical experiment, including tools that previous researchers validated. The analysis is made from different angles, using quantitative and qualitative measurements. The work has, however, limitations. The game was tested in Irish primary schools, and results might not be 
the same in different contexts. There is also difficulty measuring the efficacy and legitimacy of educational practices as several variables must be considered and can influence the experiment results.

The results suggest Once Upon a Maths significantly increased the learning outcomes, which might be related to the fact narrative-based learning leads students to connect the concepts learned to the human experience [71], giving meaning to abstract concepts. Once Upon a Maths did not affect the MA levels considering the whole group of students but increased those levels for the female students in one classroom. The effect size of the game on increasing the levels of MA in female students was small. Therefore, other variables might have affected those levels. It is important to highlight that this classroom where females got more anxious was in the second class of the primary school. In Ireland, the second class is when students take a standardised exam for the first time in their school life. These tests are administered, scored, and interpreted according to a set of rules. Irish primary schools are required to administer standardised tests in English reading and math in second, fourth, and sixth classes and report the aggregated results to their Boards of Management and the Department of Education and Skills. In 2019, researchers showed that three out of four primary teachers agree that primary school pupils get anxious about standardised tests. The study collected 1,500 primary school teachers opinions [72]. Previous research has shown that standardised tests also influence how students in Ireland feel about mathematics. Therefore, our results might be related to the anxiety female students were feeling about the standardised test.

Previous researches suggest many factors can explain why girls have higher MA levels than boys. Exposure to negative attitudes about math by role models like parents and teachers, a higher possibility of feeling anxious when seeing another child with anxiety, and exposure to gender stereotypes are only a few reasons that might lead girls to have higher anxiety than boys [36], [73], [74]. The way students build their social relationships plays a huge importance in their learning outcomes [75]. Classroom studies can be challenging as a number of variables not always predicted during the research design. The MA levels of a student can be influenced not only by aspects of the classroom environment but also by the parents' MA levels [76]. Furthermore, females levels of MA can be influenced by aspects such as how they perceived their math abilities and their teachers' abilities [77]. In our future studies, we plan to consider the particularities of each student and the environment where math is learned, including teachers' and parents' MA levels.

The group interview results suggested that the idea of transposing the history of maths] into a game allowed students to interact and be part of this narrative. In fact, storytelling can be quite powerful for math education. They make mathematics more meaningful and provide a context, besides allowing children to connect to other areas of childhood [78]. The group interviews illustrated how the storytelling and presence of characters helped children to engage with the game. Using the history of math as a narrative for the game may help students comprehend that math is part of our society, making it more natural and less frightening. 


\section{References}

[1] H. P. Ginsburg, J. Cannon, J. Eisenband, and S. Pappas, "Mathematical Thinking and Learning," Blackwell Handb. Early Child. Dev., pp. 208-229, 2006, doi: 10.1002/9780470757703.ch11.

[2] D. H. Clements and J. Sarama, "Effects of a preschool mathematics curriculum: Summative reserach on the Building Blocks project," J. Res. Math. Educ., vol. 38, no. 2, pp. 136-163, 2007, doi: 10.2307/30034954.

[3] P. (UCC) Conway and F. (Arizona S. U. Sloane, "International Trends in Post-Primary Mathematics Education: Perspectives on learning, teaching and assessment," no. 5, p. 295, 2006, [Online]. Available:

http://www.ncca.ie/en/Publications/Reports/International_trends_in_postprimary_mathematics_education.pdf.

[4] P. Ernest, "Popularization: Myths, Massmedia and Modernism," in International Handbooks of Mathematics Education, A. J. Bishop, K. Clements, C. Keitel, J. Kilpatrick, and C. Laborde, Eds. The Netherlands: Kluwer Academic Publishers, 1996, p. 33.

[5] S. Caviola, E. Carey, I. C. Mammarella, and D. Szucs, "Stress, time pressure, strategy selection and math anxiety in mathematics: A review of the literature," Front. Psychol., vol. 8, no. SEP, pp. 1-13, 2017, doi: 10.3389/fpsyg.2017.01488.

[6] B. R. J. Jansen, J. Louwerse, M. Straatemeier, S. H. G. Van der Ven, S. Klinkenberg, and H. L. J. Van der Maas, "The influence of experiencing success in math on math anxiety, perceived math competence, and math performance," Learn. Individ. Differ., vol. 24, pp. 190-197, 2013, doi: 10.1016/j.lindif.2012.12.014.

[7] M. Mcmullan, R. Jones, and S. Lea, "Math anxiety, self-efficacy, and ability in British undergraduate nursing students," Res. Nurs. Heal., vol. 35, no. 2, pp. 178-186, 2012, doi: 10.1002/nur.21460.

[8] H. H. Bruce D. Homer, Charles Raffaele, "Game as Playful Learning: Implications of Developmental Theory for Game-Based Learning," in Hanbook of Game-Based Learning, B. Jan L. Plass, Richard E. Mayer, Ed. London: MIT Press, 2020, pp. 25-52.

[9] K. Chang, L. Wu, S. Weng, and Y. Sung, "Computers \& Education Embedding game-based problem-solving phase into problem-posing system for mathematics learning," Comput. Educ., vol. 58, no. 2, pp. 775-786, 2012, doi: 10.1016/j.compedu.2011.10.002.

[10] M. Bakker, M. van den Heuvel-Panhuizen, and A. Robitzsch, "Effects of playing mathematics computer games on primary school students' multiplicative reasoning ability," Contemp. Educ. Psychol., vol. 40, pp. 55-71, 2015, doi: 10.1016/j.cedpsych.2014.09.001.

[11] M. Rocha and P. Dondio, "Design and evaluation of an adventure videogame based in the history of mathematics," in 9th International Conference GALA 2020, 2020, pp. 1-10.

[12] R. Tahir and A. I. Wang, "Codifying Game-Based Learning: Development and Application of LEAGUÊ Framework for Learning Games," Electron. J. e-Learning, vol. 17, no. 4, pp. 69-87, 2020, doi: 10.34190/JEL.18.1.006.

[13] B. Gros, "Game Dimensions and Pedagogical Dimension in Serious Games," in Handbook of Research on Serious Games for Educational Applications, R. Zheng and M. K. Gardner, Eds. Hershey: IGI Global, 2016, p. 495.

[14] F. Ke and K. Building, "Classroom Goal Structures for Educational Math Game Application," pp. 314-320, 2006.

[15] E. Afari, J. M. Aldridge, B. J. Fraser, and M. S. Khine, "Students' perceptions of the learning environment and attitudes in game-based mathematics classrooms," Learn. Environ. Res., vol. 16, no. 1, pp. 131-150, 2013, doi: 10.1007/s10984-012-9122-6.

[16] A. Bray and B. Tangney, "Technology usage in mathematics education research - A systematic review of recent trends," Comput. Educ., vol. 114, pp. 255-273, 2017, doi: 10.1016/j.compedu.2017.07.004.

[17] T. Hainey, T. M. Connolly, E. A. Boyle, A. Wilson, and A. Razak, "A systematic literature review of games-based learning empirical evidence in primary education," Comput. Educ., vol. 
102, pp. 202-223, 2016, doi: 10.1016/j.compedu.2016.09.001.

[18] W. Watson and S. Yang, "Games in schools: Teachers' perceptions of barriers to game-based learning," J. Interact. Learn. Res., vol. 27, no. 2, pp. 153-170, 2016.

[19] C. Smarkola, "Developmentally Responsive Technology-Literacy Use in Education: Are Teachers Helping Students Meet Grade-Level National Technology Standards?," J. Educ. Comput. Res., vol. 38, no. 4, pp. 387-409, 2008, doi: 10.2190/EC.38.4.b.

[20] F. A. Inan, D. L. Lowther, S. M. Ross, and D. Strahl, "Pattern of classroom activities during students' use of computers: Relations between instructional strategies and computer applications," Teach. Teach. Educ., vol. 26, no. 3, pp. 540-546, 2010, doi: 10.1016/j.tate.2009.06.017.

[21] K. Devlin, Mathematics Education for a New Era: Video Games as a Medium for Learning. Natick, Massachusetts: A K Peters, 2011.

[22] E. Lehtinen, M. Hannula-Sormunen, J. McMullen, and H. Gruber, "Cultivating mathematical skills: from drill-and-practice to deliberate practice," ZDM - Math. Educ., vol. 49, no. 4, pp. 625-636, 2017, doi: 10.1007/s11858-017-0856-6.

[23] J. R. Anderson, L. M. Reder, and H. A. Simon, "Situated Learning and Education Situated Learning and Education'," Source Educ. Res., vol. 25, no. 4, pp. 5-11, 1996, doi: $10.2307 / 1176775$.

[24] S. Waite and N. Pratt, "Theoretical perspectives on learning outside the classroom: relationships between learning and place," in Children Learning Outside the Classroom: From Birth to Eleven, SAGE, 2011, pp. 7-21.

[25] K. Squire, "From Content to Context: Videogames as Designed Experience," Educ. Res., vol. 35, no. 8, pp. 19-29, 2006, doi: 10.3102/0013189X035008019.

[26] G. B. Karaduman, "A sample study for classroom teachers addressing the importance of utilizing history of math in math education," Procedia - Soc. Behav. Sci., vol. 2, no. 2, pp. 2689-2693, 2010, doi: 10.1016/j.sbspro.2010.03.397.

[27] M. Kool, "An extra student in your classroom: How the history of Mathematics can enrich interactive mathematical discussions at primary school," Math. Sch., pp. 19-22, 2003.

[28] A. Bakker and K. P. E. Gravemeijer, "An historical phenomenology of mean and median," Educ. Stud. Math., vol. 62, no. 2, pp. 149-168, 2006, doi: 10.1007/s10649-006-7099-8.

[29] M. Dejić and A. Mihajlović, "History of Mathematics and Teaching Mathematics," Teach. Innov., vol. 27, no. 3, pp. 15-30, 2014.

[30] E. J. Dias, C. Fernando, A. Jr, and M. A. Ota, "Tablets and applications to tell Mathematics History in High School," in 13th International Conference Mobile Learning 2017, 2017, pp. $11-17$.

[31] Y. Hong and P. Chen, "The application of HPM video clips in mathematical teaching in middle school : Teaching the application of linear equation with one unknown," in History and Pedagogy of Mathematics, 2016, pp. 1-12.

[32] G. Ramirez, E. A. Gunderson, S. C. Levine, and S. L. Beilock, "Math Anxiety, Working Memory, and Math Achievement in Early Elementary School Math Anxiety, Working Memory, and Math Achievement in Early Elementary School," J. Cogn. Dev., no. October 2014, pp. 37-41, 2013, doi: 10.1080/15248372.2012.664593.

[33] X. Ma, "A meta-analysis of the relationship between anxiety toward mathematics and achievement in mathematics," J. Res. Math. Educ., vol. 30, no. 5, pp. 520-540, 1999, doi: $10.2307 / 749772$.

[34] J. Hunsley and S. L. Flessati, "Gender and mathematics anxiety: The role of math-related experiences and opinions," Anxiety Res., vol. 1, no. 3, pp. 215-224, 1988, doi: 10.1080/08917778808248720.

[35] O. Rubinsten, N. Bialik, and Y. Solar, "Exploring the relationship between math anxiety and gender through implicit measurement," Front. Hum. Neurosci., vol. 6, no. SEPTEMBER, pp. 1-11, 2012, doi: 10.3389/fnhum.2012.00279.

[36] H. I. Van Mier, T. M. J. Schleepen, and F. C. G. Van den Berg, "Gender differences regarding the impact of math anxiety on arithmetic performance in second and fourth graders," Front. 
Psychol., vol. 9, no. JAN, pp. 1-13, 2019, doi: 10.3389/fpsyg.2018.02690.

[37] X. Ma and J. Xu, "The causal ordering of mathematics anxiety and mathematics achievement: A longitudinal panel analysis," J. Adolesc., vol. 27, no. 2, pp. 165-179, 2004, doi: 10.1016/j.adolescence.2003.11.003.

[38] Z. Wang et al., "Who is afraid of math? Two sources of genetic variance for mathematical anxiety," J. Child Psychol. Psychiatry Allied Discip., vol. 55, no. 9, pp. 1056-1064, 2014, doi: $10.1111 /$ jcpp. 12224 .

[39] N. Madjar, G. Zalsman, A. Weizman, S. Lev-Ran, and G. Shoval, "Predictors of developing mathematics anxiety among middle-school students: A 2-year prospective study," Int. J. Psychol., vol. 53, no. 6, pp. 426-432, 2018, doi: 10.1002/ijop.12403.

[40] A. Henslee and B. Klein, "Using Brief Guided Imagery to Reduce Math Anxiety and Improve Math Performance: A Pilot Study," J. STEM Educ., vol. 18, no. 4, p. 32, 2017.

[41] K. Supekar, T. Iuculano, L. Chen, and V. Menon, "Remediation of childhood math anxiety and associated neural circuits through cognitive tutoring," J. Neurosci., vol. 35, no. 36, pp. 1257412583, 2015, doi: 10.1523/JNEUROSCI.0786-15.2015.

[42] T. S. Samuel and J. Warner, “II Can Math!': Reducing Math Anxiety and Increasing Math Self-Efficacy Using a Mindfulness and Growth Mindset-Based Intervention in First-Year Students," Community Coll. J. Res. Pract., vol. 00, no. 00, pp. 1-18, 2019, doi: 10.1080/10668926.2019.1666063.

[43] S. F. Verkijika and L. De Wet, "Using a brain-computer interface (BCI) in reducing math anxiety: Evidence from South Africa," Comput. Educ., vol. 81, pp. 113-122, 2015, doi: 10.1016/j.compedu.2014.10.002.

[44] J. D. C. Reyes, "Increasing Self-efficacy and Alleviating Anxiety using Touch Math and Instructional Games: An Intervention for Low Performing Seventh Graders," J. Humanit. Educ. Dev., vol. 1, no. 2, pp. 59-74, 2019, doi: 10.22161/jhed.1.2.2.

[45] I. V. S. Mullis, M. O. Martin, P. Foy, and M. Hooper, "Trends in International Mathematics and Science Study," 2015. [Online]. Available: http://timss2015.org/timss2015/science/student-achievement/distribution-of-science-achievement/.

[46] L. Kavanagh, G. Shiel, L. Gilleece, and J. Kiniry, "The 2014 National Assessments of English Reading and Mathematics Volume II: Context Report,” Dublin, 2015. [Online]. Available: www.erc.ie/NA2014.

[47] E. Smyth, "Growing Up in Ireland OFF TO A GOOD START? Primary School Experiences and the Transition to Second-Level Education," Dublin, 2017. [Online]. Available: www.dcya.ie.

[48] C. Lane, M. Stynes, and J. O'Donoghue, "The image of mathematics held by Irish postprimary students,” Int. J. Math. Educ. Sci. Technol., vol. 45, no. 6, pp. 879-891, 2014, doi: 10.1080/0020739X.2014.884648.

[49] M. Rocha, "Investigation of the effects of a situated learning digital game on mathematics education at the primary school level," Technological University Dublin, 2020.

[50] E. Dunphy, "The primary mathematics curriculum: enhancing its potential for developing young children's number sense in the early years at school," Irish Educ. Stud., vol. 26, no. 1, pp. 5-25, 2007, doi: 10.1080/03323310601125088.

[51] E. Ju and C. Wagner, "Personal computer adventure games," ACM SIGMIS Database, vol. 28, no. 2, pp. 78-92, 1997, doi: 10.1145/264701.264707.

[52] M. D. Dickey, "Game design narrative for learning: Appropriating adventure game design narrative devices and techniques for the design of interactive learning environments," Educ. Technol. Res. Dev., vol. 54, no. 3, pp. 245-263, 2006, doi: 10.1007/s11423-006-8806-y.

[53] M. Ninas, S. de Freitas, and K. Kiili, "Motivational Potential of Leaderboards in a Team-Based Math Game Competition Manuel," in Games and Learning Alliance conference, 2020.

[54] B. Nazar, "Examining the Symbolic Meaning of Colors," no. November, 2017.

[55] F. Carelli, "The book of death: Weighing your heart," London J. Prim. Care (Abingdon)., no. 1, pp. 87-88, 2011, doi: 10.1080/17571472.2011.11493336.

[56] G. Stoet, D. H. Bailey, A. M. Moore, and D. C. Geary, "Countries with higher levels of gender equality show larger national sex differences in mathematics anxiety and relatively lower 
parental mathematics valuation for girls," PLoS One, vol. 11, no. 4, 2016, doi: 10.1371/journal.pone.0153857.

[57] P. Pruet, C. S. Ang, and D. Farzin, "Understanding tablet computer usage among primary school students in underdeveloped areas: Students' technology experience, learning styles and attitudes," Comput. Human Behav., vol. 55, pp. 1131-1144, 2016, doi: 10.1016/j.chb.2014.09.063.

[58] M. N. Giannakos, K. Chorianopoulos, L. Jaccheri, and N. Chrisochoides, "“This game is girly!' Perceived enjoyment and student acceptance of edutainment," Lect. Notes Comput. Sci. (including Subser. Lect. Notes Artif. Intell. Lect. Notes Bioinformatics), vol. 7516 LNCS, no. 246016, pp. 89-98, 2012, doi: 10.1007/978-3-642-33466-5_10.

[59] T. Hartmann and C. Klimmt, "Gender and computer games: Exploring females' dislikes," $J$. Comput. Commun., vol. 11, no. 4, pp. 910-931, 2006, doi: 10.1111/j.1083-6101.2006.00301.x.

[60] The Lydian Hill Foundation and The Geena Davis Institute on Gender in Media, "Portray her: Representations of women STEM characters in media," pp. 1-29, 2018, [Online]. Available: https://seejane.org/wp-content/uploads/portray-her-full-report.pdf.

[61] Accenture, "Powering economic growth; Attracting more young women into science and technology," 2014. [Online]. Available: https://accntu.re/3dB3ynZ.

[62] I. Caleon and S. Ramanathan, "From music to physics: The undervalued legacy of pythagoras," Sci. Educ., vol. 17, no. 4, pp. 449-456, 2008, doi: 10.1007/s11191-007-9090-x.

[63] J. Fuegi and J. Francis, "Lovelace \& babbage and the creation of the 1843 'Notes," Ada User J., vol. 36, no. 2, pp. 89-98, 2003.

[64] J. Essinger, Ada's Algorithm? How Lord Byron's daughter Ada Lovelace launched the digital age. London: Melville House, 2014.

[65] P. Dugard and J. Todman, "Analysis of Pre-test-Post-test Control Group Designs in Educational Research," Educ. Psychol., vol. 15, no. 2, pp. 181-198, 1995, doi: 10.1080/0144341950150207.

[66] E. Carey, F. Hill, A. Devine, and D. Szucs, "The modified abbreviated math anxiety scale: A valid and reliable instrument for use with children," Front. Psychol., vol. 8, no. JAN, pp. 1-13, 2017, doi: 10.3389/fpsyg.2017.00011.

[67] C. Kelleher and S. Weir, "Class Size and Student-Teacher Ratio At Primary Level in Ireland and Other Oecd Countries," Irish J. Educ., pp. 39-60, 2016.

[68] D. P. S. Henderson, "Exploring the Impact of a Mindfulness-Based Intervention in Relation to Primary School Children's Mathematics Anxiety," University of Exeter, 2019.

[69] A. J. Devine, "Cognitive and emotional mathematics learning problems in primary and secondary school students," University of Cambridge, 2017.

[70] J. Cohen, Statistical power analysis for the behavioral sciences, 2nd ed. New York: Lawrence Erlbaum Associates, 1988.

[71] L. Hobbs and R. Davis, "Narrative Pedagogies in Science, Mathematics and Technology," Res. Sci. Educ., no. June, 2012, doi: 10.1007/s11165-012-9302-5.

[72] M. O'Leary, Z. Lysaght, D. Nic Craith, and D. Scully, "Standardised testing in English reading and mathematics in the Irish primary school: A survey of Irish primary teachers," Dublin, 2019.

[73] S. L. Beilock, E. A. Gunderson, G. Ramirez, and S. C. Levine, "Female teachers' math anxiety affects girls' math achievement," Proc. Natl. Acad. Sci. U. S. A., vol. 107, no. 5, pp. 18601863, 2010, doi: 10.1073/pnas.0910967107.

[74] E. A. Maloney, J. R. Sattizahn, and S. L. Beilock, “Anxiety and cognition,” Wiley Interdiscip. Rev. Cogn. Sci., vol. 5, no. 4, pp. 403-411, 2014, doi: 10.1002/wcs.1299.

[75] H. Patrick, L. H. Anderman, and A. M. Ryan, "Social motivation and the classroom social environment," in Goals, goal structures, and patterns of adaptive learning., no. January 2002, 2002, pp. 85-108.

[76] B. J. Casad, P. Hale, and F. L. Wachs, "Parent-child math anxiety and math-gender stereotypes predict adolescents' math education outcomes," Front. Psychol., vol. 6, no. NOV, pp. 1-21, 2015, doi: 10.3389/fpsyg.2015.01597. 
pag. 70

[77] A. F. Haynes, A. G. Mullins, and B. S. Stein, "Differential models for math anxiety in male and female college students," Sociol. Spectr., vol. 24, no. 3, pp. 295-318, 2004, doi: 10.1080/02732170490431304.

[78] B. Casey, J. E. Kersh, and J. M. Young, "Storytelling sagas: An effective medium for teaching early childhood mathematics," Early Child. Res. Q., vol. 19, no. 1, pp. 167-172, 2004, doi: 10.1016/j.ecresq.2004.01.011. 